\title{
WHO announces new initiative to fight SARS and other diseases
}

The WHO has announced the creation of a new public-private initiative to fight SARS, ${ }^{*}$ and to build capacity for surveillance, epidemiology and public health laboratories in China and the surrounding region.

Director general Elect of the WHO Dr Jong-Wook Lee says that, "despite the rapid and effective response from partners around the world, SARS exposes fundamental weaknesses in global health infrastructure". The WHO initiative, and other similar funding initiatives, will help prepare the world to respond to future emerging diseases, adds $\mathrm{Dr}$ Lee. The international business community has pledged its support to mobilise the initial resources needed to carry out the work through a special fund.

The initial target is to raise $\$$ US100 million by September this year from the business community, particularly from companies with operations or markets in Asia. An additional \$US100 million will be raised by the WHO from bilateral donors to support expanded disease surveillance and response across the globe. Executive director for communicable diseases at the WHO, Dr David Heyman, says that "the money will be disbursed rapidly, to get to the areas that need it most as quickly as possible". He adds that this "sense of urgency" is due to the belief that "there remains a window in which we can control SARS and eliminate the global threat it poses - forever".

* severe acute respiratory syndrome

World Health Organization. World Health Organization announces new publicprivate initiative on disease surveillance and response. Media Release : 22 May 2003. Available from: URL: http://www.who.it 